\title{
Delivering Creative Education for Health Promoters in Africa-Towards Critical Mass by "Going Global and Staying Local”
}

\author{
Rachael Dixey \\ Institute of Health and Wellbeing, Leeds Metropolitan University, Leeds, UK \\ Email: R.Dixey@leedsmet.ac.uk
}

Received August $1^{\text {st }}$, 2012; revised September $5^{\text {th }}$, 2012; accepted September $16^{\text {th }}, 2012$

\begin{abstract}
Postgraduate opportunities for health promotion and other courses allied to health are limited in sub-Saharan Africa (apart from South Africa). There are major constraints on the development of health promotion in sub-Saharan Africa, and the lack of training capacity is one of them. Although potential students can access courses in parts of the global North where health promotion is strong-Europe, North America, Australia - this option is expensive. It also takes workers away from their posts for considerable periods and can be gender-biased. This paper describes a creative educational approach where postgraduate study is taken to Africa, from the UK, in the attempt to create communities of learning and to develop a critical mass of health promotion workers, such that they can make real change to the infrastructure for health promotion and thus to the health of the populations of their countries. In studying at home however, there is a debate to be had about whether this fulfills one goal of higher study, which is to develop cross-cultural awareness and the mindset of the "global citizen". The paper thus questions whether it is "better" to stay local or go global. The postgraduate course we teach in Zambia and The Gambia does seem to provide this global awareness as well as enabling health promotion workers to develop their practice, and moreover it has the capacity to develop the critical mass of workers needed to create the momentum for change.
\end{abstract}

Keywords: Africa; Health Promotion; Global Citizenship; Public Health Training

\section{Introduction: Health Promotion and Capacity in Sub-Saharan Africa}

As providers of postgraduate education, we have seen the trend of increasingly expensive courses in developed countries such as the UK, and the decrease of scholarships, together with the difficulties of individual international students returning to their countries, enthused with new ideas, but unable to make an impact on the structures within which they work. The Leeds Metropolitan University course in health promotion has an international reputation, and apart from its home students, attracts students predominantly from Africa, plus a few from Asia and the Middle East. The establishment of scholarships from the Commonwealth Scholarships Commission for distance courses led to us submitting a bid to run the course in Lusaka, Zambia, in partnership with Chainama College of Health Sciences there. In short, the initial bid and subsequent bids have been successful, and we have run the course (MSc Public Health-Health Promotion and Environmental Health), since 2004 in Lusaka, for six cohorts of public health workers. Later, we also set up the same provision in The Gambia, where we have run three cohorts. The purpose of this paper is to reflect on the advantages and disadvantages of running a postgraduate course in another host country, and whether by staying incountry, students miss out on a more global experience; the paper also asks whether the advantage of creating a critical mass of learners outweighs other considerations. By "critical mass" is meant a number of learners sufficient to create change. The paper also asks whether our approach really represents creative education, or is simply a pragmatic solution to the lack of capacity in Africa.

Health promotion is sometimes regarded as the radical wing of public health; it is not to be confused with, or used interchangeably with, health education. Although health education (intended to provide information and education to the public about how to protect their health), is part of health promotion, health promotion is concerned with tackling the social determinants of health and health inequalities. It works "upstream", usually at a policy level. To take a concrete example, a health promotion officer tackling an issue such as obesity would work with transport planners to persuade them to prioritise healthier means of getting around such as walking and cycling, with schools to develop healthier school food, with the food industry to do likewise, and so on. The Ottawa Charter (WHO, 1986) provides the central document upon which modern health promotion rests; it lists five areas for action, namely building healthy public policy, providing supportive environments, building strong communities, developing personal skills and reorienting health services. A major task is to wrest "health" from health care services (which are really sickness services) and move the agenda into health and wellbeing, or into a "salutogenic" mindset. Whereas pathogenesis is concerned with what causes illness and disease, salutogenesis is concerned with what causes wellness and health. Those educated within a traditional health care model find this mind-shift difficult, and it is one of the aims of the course to achieve this. The place to create 
health mainly lies outside the health care sector, and 'upstream'. Health promoters are thus expected to be able to plan, implement and evaluate actions that promote health, and to develop skills in partnership working, empowering communities, strategic thinking, project management, and to apply theory to their practice.

Sub-Saharan Africa generally, South Africa excepted, (Van den Brouke et al., 2010) has a dearth of training capacity for health promotion (Onye, 2009). It does have diploma courses in health education, but does not have good quality postgraduate health promotion courses reflecting the Ottawa Charter philosophy. Capacity for higher education is limited in general, and not just in relation to health courses. Whereas African universities are acknowledged to have performed well in producing human resources (Ajayi et al., 1996), they have done this against a background where before 1960, only 18 of 48 subSaharan countries had a university (Sawyerr, 2004). The neglect of secondary schooling during the colonial period left many countries without potential university candidates (Dixey, 1997) and even today, it is noticeable that the education systems of some sub-Saharan countries are more developed than others. Despite the development of African Universities, they run the risk of becoming marginalized in the interconnected global knowledge economy of the 21st century, where Universities in the global North have been on a marketization trajectory for many years. Obamba (2010: p. 350), studying the higher education sector in Kenya, suggests that the sector needs to be bold, and "urgently institute effective policy measures that can ensure increased liberalization”, together with dismantling the rigid boundaries between the private and public universities. Better conditions are required in order to keep academics in public Universities (Afful-Broni \& Nanyele, 2012), as many leave for Universities in "developed" parts of the world. The move of academics is mirrored by the movement of graduates, and the trend for "brain gain" to become "brain drain" was noted by Carrington and Detragiache (1999) who asked the question back in the1990s as to whether the universities and training institutions of Africa were servicing the demands of developed countries, due to the migration of health professionals trained in Africa.

\section{Towards Larger Numbers of Learners and Communities of Learning}

Shifting countries with a high disease burden into a more "social" model of health and away from the medical dominance of public health has been identified by African colleagues as a central task in order for health promotion to develop in Africa (Nyamwaya, 2003, 2005; Amunyunzu-Nyamongo \& Nyamwaya, 2009). As one of our Zambian students commented,

"In Zambia we have along way to go to start appreciating the importance of health promotion. Our services are predominantly centred on treatment, prevention and control of diseases. The main objective of the health services is to improve affordability and accessibility of health services and not to create a healthy community. A lot of money goes to the procurement of drugs, medical supplies and building of health centres while health promotion programmes do not receive the necessary support they deserve from the government. There is need for high level advocacy on the need for directly funded, centrally co-ordinated health promotion programmes with an intersectoral approach with offices in all the districts." (Zambia cohort 4, 2009)

This is a tall order anyway, but is even more so when countries can only afford to send small numbers of students annually to be trained in this way of thinking; individual students return to their often inert bureaucracies and slot back into the organization's way of doing things. Frustrated by the slow pace of change in ministries, they often leave to work in the NGO sector. Moreover, sending students to developed countries is expensive and a range of other issues might arise: students may not return to their home country, the selection process might not be fair within the home country, selection can be genderbiased, workers are absent for considerable periods of time, and the course they attend might not have direct applicability. That said, many students gain enormously from the experience, and do indeed return to make real differences in their home nations. It is a costly process however, and in today's more straitened financial times, it can be questioned.

The development of a distance learning strand by the Commonwealth Scholarships Commission (CSC) provided an opportunity to bid for funding to run the course in Zambia, taking the course to the students rather than expecting them to come to Leeds. An in-country course delivery model became feasible due to funding from the CSC, the willingness of Leeds Met to enable off-site delivery, and the partnership already existing with Chainama College, Lusaka. Preliminary visits from the core staff enabled a partnership approach to curriculum development and the recruitment and selection strategy, ensuring it fitted with Ministry of Health human resource needs. It was agreed that face-to-face delivery was the only viable option at the time given the level of IT resources. A model emerged of teaching modules in blocks of two weeks, with eight blocks over two years followed by a period collecting data and writing a dissertation.

The course was initially designed to give Chainama College teaching staff the opportunity to gain a Masters qualification; some of these staff members are tutors working in remote rural areas. All are essential to the training of the health workforce in Zambia, as they teach the frontline workers-clinical officers, nurses, environmental health officers. There was therefore, a clear need for capacity building at the College, which wanted to pursue being granted University status. Numerous spin-offs occurred including gaining funding for staff travel in both directions for research projects, opportunities for Zambian staff to learn about the administration and financial arrangements at Leeds Met, and the attraction of additional projects to enable health workers from Leeds to provide support at Chainama Hospital.

Subsequent cohorts widened to include those working in other health sectors in Zambia and from other higher education colleges. This widening has continued into the sixth cohort though Chainama is still the central location for the course. 150 students have enrolled in the programme, with approximately half supported by CSC scholarships. The course is entirely "owned" by Leeds Met and conforms to its quality assurance processes. Tutors from Leeds Met travel to Lusaka for the teaching blocks, providing an intensive workshop style student experience. Local experts are also included as guest lecturers and more recently, local tutors have teamed up with Leeds Met staff so that they can ultimately run postgraduate courses themselves. A well thought through process of local support was established, employing local staff to support students both personally and academically in the interim months. This provides 
professional experience, a small income and kudos as well as meeting the needs of students. Senior staff at Chainama provide administrative support and advice.

Paying Chainama College for use of facilities enables a flow of income to a relatively resource-poor college, which has in turn been able to upgrade its premises. Increased confidence and morale, plus more tangible benefits such as being able to attract other development funds and additional partnerships, are apparent alongside the staff capacity building. This brief overview of the delivery may make the project look simple, but cannot detail the large amount of work that has gone into planning, logistics, or relationship building. Some of this detail has been recorded elsewhere (Dixey \& Green, 2009).

The course developed in The Gambia in the same way, following requests from our Leeds graduates to deliver the course there. So far, three cohorts have enrolled, totaling 94 students, partly funded by the CSC, the National AIDS Secretariat and additional self-funders. The Gambian provision was also advertised in Sierra Leone and has included 20 students from there, who travel to The Gambia for each module. As in Zambia, the course has advantages of local delivery, enabling it to be made relevant to the local situation, enabling health workers to remain in situ and being able to apply their learning immediately after a teaching block.

The drop out rate for the course is lower than that found for courses run in the UK, and the completion rate is also high. We did underestimate the speed at which students would be able to complete their final dissertations, mainly due to the need to remedy the lack of research experience. However, in terms of creating a critical mass, the courses have achieved that. Whether this critical mass will then go on to produce the kinds of organizational changes and challenge the status quo remains to be seen. The fact that the course has created a community of learners (Lave \& Wenger, 1998), improved networking and broken down some of the inter-professional barriers does bode well.

So far, there is a suggestion that local is "better", that the mode of delivery restricts the need for travel, resonating with Naidu's (2006: p. 1), comment that "learning and cognition are most potent when situated within a meaningful context, and within the culture and community within which learners live". There are substantial benefits of postgraduate study overseas however, as expressed by our students studying in Leeds (Dixey, 2001). The "local or global" debate is discussed further in the next section.

\section{Studying Locally, Thinking Globally?}

British universities have stressed in recent years not only employability but also the development of graduates as individuals who can contribute to a globalising world, leading to the emergence of the idea of "global citizenship". In being able to respond to the perceived challenges of globalisation, "it is essential that our institutions of higher education graduate globally competent students" (Brustein, 2007: p. 3). There is also emphasis on 'cross-cultural capability'; at Leeds Metropolitan University for example, we have to show in all our course validation documents, how students are being educated in terms of cross-cultural capability, enabling them to develop intercultural competence and by extension, intercultural citizenship (Alred et al., 2006). Students study in Leeds in very internationally mixed groups and are exposed to various political, religious and cul- tural differences. It was challenging therefore, to demonstrate how our Masters course would deliver "cross-cultural capability” when taught in the students' home country. Inevitably, the cohorts within country are more homogenous and although we as staff challenge students hard in terms of diversity, equality and human rights, they are not exposed in the same way to a broad range of students from different backgrounds.

The quality of learning implied in cross-cultural capability is of "deep learning"-students are not only expected to take in "knowledge" but are expected to learn "to be", to somehow develop their identity as well as learning "to do". As such, this learning challenges what Bordieu refers to as "doxa", which Charlesworth describes as the way in which people accept their culture and environment as "natural" and as given, as this is what they know and have been brought up with. Doxa "refers to that which we think from rather than that which we think about" (Charlesworth, 2000: p. 30). Deep learning implies that people will move the horizons of their life world, from their self-world, socio-cultural world, into the extended world. Postgraduate education has to push the boundaries.

In moving countries, moving into the extended world, students are confronted with cultures that are strikingly or subtly different from those they have grown up in, and to which they are accustomed. It is assumed that studying abroad will develop cultural awareness and better equip students for a globalising world, that the international student will benefit in tangible ways by being removed from the supposed mono-culture of their home life and that it will lead to "extra-ordinary" learning. There is a tacit value judgement that studying abroad will be a richer experience that "staying at home". It is assumed that becoming cosmopolitan (where the intellectual self is situated outside the local) is somehow superior (Friedman, 1994). There are also claims made for international education experiences, such as that they "help improve social justice around the world" (Bremer, 2006: p. 44) or that such an experience "provokes learning about one's own view of the world and, in the process, changes the 'self'” (Fantini, 2003: p. 16). As far back as Aristotle, there was the notion that travel will lead one to appreciate the commonality of all humanity: "One may also observe in one's travels to distant countries the feelings of recognition and affiliation that link every human being to every other human being" (Aristotle, cited in Nussbaum, 1993). On a more prosaic level, international students may develop an independence, broadened outlook, greater cultural awareness and in many cases, where students are from poorer countries, access to higher standards of living and the chance to remit money home. However, a number of studies are critical of the claims made for studying overseas, more particularly of students travelling from richer countries, and that such sojourns are over-rated in both academic learning terms and in becoming a "global citizen” with enhanced cultural awareness (Gillespie, 2002; Brockington \& Wiedenhoeft, 2009).

Is it possible to fulfil the "global citizen" ambition through postgraduate education where students do not leave their home environments? We believe it is for a number of reasons: firstly students are exposed to staff from the global North with very different backgrounds who deliberately challenge students to think in new, critical ways, and who use material from a range of cultures; some students themselves have already travelled overseas and bring those experiences with them; students do access the course from a few other countries (viz. from Sierra Leone in The Gambia and in one Zambian cohort four Tanza- 
nians were present, and more recently one student from the DRC (Democratic Republic of the Congo) has enrolled), and so there is some element of cultures meeting. Finally, there is considerable input on globalisation, global health and global governance.

One small example of students being challenged occurred recently in the first module of the latest cohort in Zambia. As health promotion involves many issues of morality, legality and sensitive areas in sexuality and personal behaviours, one of the exercises we do is to ask students to consider behaviours that are legal or illegal, moral or immoral. Invariably, they place "homosexuality" in the "illegal and immoral" category. Invariably, of course, staff challenge this view. What really made a difference to their views was one student who had worked in the USA talking about how she had friends who were gay, and secondly, my own statements about how "gay rights are human rights" and to me, being gay or straight was equally "moral". What really made the difference however, was my saying how shocked I was that in Zambia, the main risk factor for women acquiring HIV was being married, with the key issue being multiple concurrent partners. In Zambia, HIV prevalence is $14 \%$; I asserted that in the UK, the rates are so low that we do not give them as a percentage, but as a rate per 10,000. Multiple concurrent partners is seen as a norm, albeit a regrettable one, in Zambia, and realising that this was shocking to an outsider was in turn a shock to the students. This relatively small incident palpably demonstrated to them that their culture was not 'normal' in someone else's eyes. It was cheering to hear at the end of the module that a number of students, all of who are mature adults with careers, to say that they had moved in their views, and had at least realised that they needed to respect other cultures even if they didn't always agree with them.

A second example of challenging the students is to take them on fieldwork in rural areas. Zambia has one of the highest rates of urbanisation in Africa, and unlike other countries, where people still have links to the villages in which they were often born, in Zambia, there are third or fourth generation urban dwellers. Filed work in rural villages is described as a major culture shock by many of the students experiencing it; the Communities and Community Health module requires several days talking to local people about their lives. Thomas (1999) describes the transformation that can take place even in brief encounters with others; in this case, such transformation occurred through hearing the stories of local people and thus connecting with the life worlds of "the other". As staff we have been taken by surprise at this impact on the Zambian students, whereas in The Gambia and Sierra Leone, students seem more in tune with their rural origins. Even for the latter, it is hoped that that studying one's own community can lead to becoming more globally competent. "Becoming global" requires an awareness of one's own peculiar socio-cultural context; Hunter et al. (2006) say that actually this is the most critical part of becoming globally competent. A further step is where people become aware more generally of how cultures "work", i.e. not only being aware of one's own culture but also comprehending the workings of any culture. To appreciate the workings of 'culture' generally, one still has to step outside one's own culture and this understanding can lead to an appreciation of difference, that other cultures have distinct belief systems, and that the life worlds of others have been shaped in very different ways (Bhawuk, 1998). The sociological imagination requires one to 'make strange' common sense knowledge; further, the aim of critical thinking is to be open-minded, ask challenging questions and to interrogate assumptions. It should lead students to ask uncomfortable questions about their own culture(s) and moreover, to understand their own prejudices and how their culture affects their perspective on the world. This kind of critical thinking inevitably challenges the tendency to only see the world through one's own culture's lens. As such, students cross a "threshold". In educational terms, "threshold concepts" (Meyer \& Land, 2005) suggest that these can transform one’s worldview and/or cause a "shift in perspective (that) may lead to a transformation of personal identity, a reconstruction of subjectivity” (Meyer \& Land, 2005: p. 4). Meaningful reflection, as part of critical thinking (Schon, 1987) can consolidate the significance of the experiential learning and enhance the transformation. This kind of reflection is essential at postgraduate level and is a new way of learning for many students.

Another example of "making strange" common sense knowledge is when we ask a particular Zambian academic to give a talk about gender. This male colleague seriously challenges the men in the group, in a culture where students treat it as normal to discuss how to make sure their wife carries out the husband's wishes and perform their "wifely duties" properly. The fact that a Zambian male is teaching about gender is extremely potent; it enables the students to realise that gender equality cannot be dismissed as a Western intrusion.

A further example, applying in both countries, is that as we challenge the practices of the students as health practitioners, asking them to think more critically about what they are doing and why, we "stop them in their tracks". Asking them to consider the evidence base for practice from a variety of other countries, and suggesting alternative ways of doing things, including applying a theory base to practice, results in a period of discomfort and puzzlement as students question their accustomed ways of doing things. Shifting from a "medical model" of health to a "social model" is particularly challenging and trans- formative. From the point of view of an educational experience, this raises a paradox: moving beyond the familiar into a more extended world will challenge students' identity and sense of self. The ability to act (agency), flows from identity, but if deep learning challenges identity, loosening identity anchor points, then the capacity to act, to exercise agency, can be compromised in some way by that deep learning. The task of the educator of course, is to facilitate the transition through this period of confusion and to make it an exciting journey rather than a crippling one.

The question of whether it is more advantageous to study at home or to travel overseas cannot be fully answered. The benefits of each are clear, but it can also be argued that "staying at home” doesn't preclude becoming more cross-culturally aware or stop people developing a "global citizen” outlook. It's well known that travel per se doesn't open minds—some people can return home with their minds just as closed! One of the aspirations of our postgraduate education is to enable students to be "a global citizen in my village in a village that is globally connected".

Moreover, the option of travelling overseas is simply not always available, as one female student remarked, "When offered a place and a Commonwealth Distant Learning Scholarship I was overjoyed, seeing this as an opportunity to advance my education at home. I have been trying for years to get a scholarship to pursue my studies. This programme has made it possible for more people to be given the chance to pursue their 
studies than if they had to go abroad for their degrees."

Another explicit aim is to address the retention of health workers and arguably, creating graduates capable of operating globally is likely to fuel the exodus rather than stem it. However, it does seem to be the case that running a postgraduate course in-country does help retention.

\section{Impact on Students}

The impact on students of studying at postgraduate level and gaining a Masters is clear from our evaluations and student feedback. These are a few of the types of comments made by various cohorts, showing their appreciation for being able to study at home, to increase their skills, confidence and opportunities for promotion, and to develop a community of practice.

"There are multiplier effects from this course, especially because so many graduates are teachers and are passing their new knowledge onto their students. Also, in the past many students would apply for study abroad and due to strains on human resources not everyone would be allowed to go. This course allows more people to study overall, as well as study in their home country whilst continuing to work and link their learning to their situations.” (Zambia cohort 2, 2007).

"There are different types of people from different walks of life in the group and it helps to work together in class because it prepares students for collaborative working in their professional lives with communities and colleagues." (Zambia cohort 2, 2007).

"The organisation of the entire program has proven to be highly cost-effective for me. This is not only because of the awarded scholarship which you ably facilitated but also that I have been to work and earn an income for myself and family without any disruptions arising from my studies. In fact, my admittance to the program has obviously widened my suitability for job opportunities. You may wish to know that during 2005, I had 2 job offers on merit based on my curriculum vitae which also bears MPH-Health Promotion as my current study programme as well as the ability to articulate ideas during the interviews. The latter part is what excites me the most because I believe that, in part, it emanates from my self-confidence which was enhanced during the study period through group work presentations in which every one of us had to actively participate-no dodging as the class was relatively small to notice those who had not presented or contributed to the group discussions. Your emphasis on 'critical thinking' before responding has re-oriented my thought-process such that I now endeavour to always analyse and comprehend issues that deserve my attention before providing my feedback. It is probably for this reason that during the past seven or so months, my performance at work has been highly rated." (Zambia cohort 1 , 2005).

"The Master of Science in Public Health (Health Promotion and Environmental Health) was a real challenge in my life. However, before graduation I was promoted to a higher rank as Manager Planning and Development for Chama District." (Zambia cohort 1, 2005).

Another student remarked that she is now being used as a resource in her workplace and is consulted for feedback on assignments (by colleagues who are students on other courses) and on funding proposals. She has developed an advisory role, and she is seen as such a valuable person within her organization that one bid for funding was postponed because she was unavailable to comment on the proposal.

Word of mouth has marketed the course: "I heard about the course from a workmate of mine who has really improved in the way she articulates issues and her high quality skills in writing. I have always wanted to study health promotion and contribute to the society I live in, but seeing how my workmate is contributing to our livelihood and the organisation in general just gave me the final kick I needed. Mostly the critical analysis and the reading. Looking forward to developing those skills." (Zambia cohort 6, 2011).

Finally, one student gave this testimony:

"The Course has changed my life around. I would simply say that it has widened my horizon in terms of education and my employment. By this I mean to say that I have been promoted three times in the civil service which is not usually the case and it's not usually easy to achieve... The time I was starting the programme I was working for ministry of commerce and trade. The course enabled me to be transferred to the ministry of health on a promotional basis from just being an economist to being a senior Planner.

1) My new job involves resource mobilization;

2) donor coordination through the SWAp mechanism (this was my research/dissertation topic);

3) publications of health related books - I was coordinating the review and production of our National Health Strategic Plan 2011-2015; participated in the institutionalisation of the $\mathrm{Na}$ tional Health Accounts, participated in the designing of Social health Insurance and the new resource allocation formula;

This is to mention but a few of my success stories in the Ministry of Health. I feel after the masters' degree I am functioning at a national level, and I am learning a lot of thing in line with my degree. I think the degree just made me look at health from a bigger picture and with a more analytical approach. For me to be at the Head quarters for the Health Sector the requirement was a Masters degree which I acquired from Leeds Met.

My vision from here is to 1) get a multinational job with the UN system so that I could contribute at a global picture; 2) to do my Ph.D. with University of Leeds metropolitan.

It is my sincere wish that the commonwealth scholarships should continue in Zambia especially that the Course at Mlevel is expensive and not easily available to a common man like me. And my thanks go to all my lecturers at Leeds Met for equipping me with educational/academic life skills." (Zambia cohort 3, 2008)

What is needed now however, is an independent evaluation of the course and its impact, and we have budgeted for this in the near future.

\section{North South Partnerships}

North-South partnerships are essential to the kind of creative solutions for the lack of educational opportunities in Africa that this provision has tried to address. Achieving equity within such partnerships is not easily achieved (Academy of Medical Sciences and Royal College of Physicians, 2012). We are aware that they rely on mutual trust and respect, recognition of each others' strengths, and that partnerships require constant maintenance and nurturing, based on secure personal relationships and strong institutional bonds. Leeds Met staff require excellent interpersonal and cross-cultural skills, a political commitment to working with partners in the global south, and imagination and creativity to overcome the inevitable challenges. Leeds Met 
staff, a mix of those with considerable experience in Africa and those with none, have all gained immensely in personal and professional terms from the opportunity to teach overseas. The richness of experience influences teaching back in the UK, and enables the enrichment of teaching material. The work in Zambia and The Gambia could not take place without supportive colleagues on the ground who can see the benefit of what we are doing. How such partnerships operate would be the subject of another paper. However, the Leeds Met-Chainama partnership was mentioned in a guide to good practice produced by the Association of Commonwealth Universities (Wanni et al., 2010), and features a picture of our students on its front cover.

\section{Conclusion}

Delivering our postgraduate health promotion course in Africa is seen as a creative solution to the lack of educational capacity in sub-Saharan Africa, and to the need for greater health promotion capacity; further, it addresses the increasing costs of students accessing courses in the global North. Developing the provision in partnership with the health worker community in Zambia and The Gambia has ensured that the course remains relevant to local needs. The loss of overseas experience and of developing "global competencies" are arguably outweighed by the possibility of developing a critical mass of Masters graduates which can effectively drive changes in public health in their respective countries. Arguably too, these global competences can be "home-grown" and studying locally doesn’t necessarily preclude their development.

\section{REFERENCES}

Academy of Medical Sciences and Royal College of Physicians (2012). Building Institutions through equitable partnerships in global health. London: The Academy of Medical Sciences.

Afful-Broni, A., \& Nanyele, S. (2012). Factors influencing worker motivation in a private African university: Lessons for leadership. Creative Education, 3, 315-321. doi:10.4236/ce.2012.33050

Ajayi, J. E. A., Lameck, K. H., Goma, G., \& Ampah, J. (1996). The African experience with higher education. Accra: Association of African Universities.

Alred, G., Byram, M., \& Fleming, M. (2006). Education for intercultural citizenship: Concepts and comparisons. Clevedon: Multilingual Matters.

Amunyunzu-Nyamongo, M., \& Nyamwaya, D. (Eds.) (2009). Evidence of health promotion effectiveness in Africa. Nairobi: African Institute for Health.

Bhawuk, D. P. S. (1998). The role of culture theory in cross-cultural training: A multimethod study of culture-specific, culture-general, and culture theory-based assimilators. Journal of Cross-Cultural Psychology, 29, 630-655. doi:10.1177/0022022198295003

Bremer, D. (2006). Global workers. International experiences help prepare global-ready graduates for the twenty-first century workforce. International Educator, 40-45. URL (last checked 16 October 2012). http://www.nafsa.org/_/File/_/global_workers_inted_2006.pdf

Brockington, J. L., \& Wiedenhoeft M. D. (2009). The liberal arts and global citizenship. Fostering intercultural engagement through integrative experiences and structured reflection. In R. Lewin (Ed.), The handbook of practice and research in study abroad (pp. 117-132). London: Routledge.

Brustein, W. (2009). It takes an entire institution: A blueprint for the global University. In R. Lewin (Ed.), The handbook of practice and research in study abroad (pp. 249-265). London: Routledge.

Carrington, W., \& Detragiache, E. (1999). How extensive is the brain drain? Finance and Development, A quarterly magazine of the IMF, $36,46-49$.

Charlesworth, S. J. (2000). A phenomenology of working class experience. Cambridge: Cambridge University Press.

Dixey, R. (1997). British involvement in educational administration in Bechuanaland 1860-1966. Journal of Educational Administration \& History, 29, 32-50.

Dixey, R. (2001). The Experience of Postgraduate study in the UK. Africa Health, May, 6-7.

Dixey, R., \& Green, M. (2009). Sustainability of the health care workforce in Africa: A way forward in Zambia. The International Journal of Environmental, Cultural, Economic and Social Sustainability, 5, 301-310.

Dovlo, D. (2005). Wastage in the health workforce: Some perspectives from African countries. Human Resources for Health, 3, 6 . doi:10.1186/1478-4491-3-6

Fantini, A. E. (2003). Academic mobility programs and intercultural competence. SIT Occasional Papers Series, 1, 25-42.

Friedman, J. (1994). Cultural identity and global process. London: Sage.

Gillespie, J. (2002). Colleges need better ways to assess study-abroad programs. Chronicle of Higher Education, 48, B20.

Hunter, B., White, G. P., \& Godbey, G. C. (2006). What does it mean to be globally competent? Journal of Studies in International Education, 10, 267-285.

Lave, J., \& Wenger, E. (1998). Communities of practice: Learning, meaning, and identity. Cambridge: Cambridge University Press.

Meyer, J, \& Land, R. (2005). Threshold concepts and troublesome knowledge (2): Epistemological considerations and a conceptual framework for teaching and learning. Higher Education, 49, 373-388.

Naidu, S. (2006). Meaningful learning in education and development, The Fourth Pan-Commonwealth Forum on Open Learning. 30 October-3 November 2006, Ocho Rios.

Nussbaum, M. (1993). Non-relative values: An Aristotlian approach. In M. Nussbaum, \& A. Sen (Eds.), The quality of life (pp. 242-269). Oxford: Clarendon.

Nyamwaya, D. (2003). Health promotion in Africa: Strategies, players, challenges and prospects. Health Promotion International, 18, 85-87.

Nyamwaya, D. (2005). Trends and factors in the development of Health Promotion in Africa, 1973-2003. In A. Scriven, \& S. Garman (Eds.), Promoting health, global perspectives (pp. 167-178). London: Palgrave.

Obamba, M. O. (2010). Betwixt public-private: Market trajectories and governance restructuring in Kenya's universities. Ph.D. Thesis, Leeds: Leeds Metropolitan University.

Onye, H. (2009). Health Promotion competency building: A call for action. Global Health Promotion, 16, 47-50.

Sawyerr, A. (2004). Challenges facing African universities: Selected issues. African Studies Review, 47, 1-59.

Schon, D. A. (1987). Educating the reflective practitioner. San Francisco, CA: Jossey-Boss.

Thomas, K. (1999). Storying for change. Community Quarterly, 5-8 June.

Van den Brouke, S., Jooste, H., Tlali, M., Moodley, V., Van Zyl, G., Nyamwaya, D. \& Tang, K.-C. (2010). Strengthening the capacity for health promotion in South Africa through international collaboration. Global Health Promotion, 17, 6-16.

Wanni, N., Hinz, S., \& Day, R. (2010). Good practices in educational partnerships guide: UK-Africa higher and further educational partnerships. London: The Africa Unit.

WHO (1986). Ottawa charter for health promotion. First International Conference on Health Promotion. Ottawa: Copenhagen WHO Regional Office for Europe. 